\section{Evaluation of cost minimization strategies of anaesthetic drugs in a tertiary care hospital}

Christopher Hawkes MD, Donald Miller MD, Raymond Martineau MD, Kathryn Hull RN, Harry Hopkins BSP, Michael Tierney MSc
A survey was undertaken to compare anaesthetic drug expenditures over a three-year period, to evaluate the impact of strategies offered to curtain continuously rising drug costs. Suggestions to control rising expenditures were based primarily on education of staff and residents regarding drug costs, emphasizing rational use of the more expensive drugs, and minimizing drug wastage. To assess the impact of these measures, a review of annual hospital budgets, global pharmacy expenditures, and anaesthetic drug expenditures was conducted for the period 1991 to 1993. Both absolute and proportional costs of anaesthetic drugs were compared, by year, according to six major classes: opioid analgesics (OA), muscle relaxants (MR), inhalational anaesthetic drugs (INH), intravenous anaesthetic drugs (IV), local anaesthetic drugs (LA) and a category labelled other drugs (OTH). In addition, the utilization patterns and unit price changes were compared for each drug for the periods 1991-92, and 1992-93. Total hospital drug costs increased from $\$ 7.1 \mathrm{M}$ to $\$ 8.5 M$ over the three years. During the same period, the cost of anaesthetic drugs decreased from $\$ 379 \mathrm{~K}$ to $\$ 361 \mathrm{~K}$, despite an augmentation in annual case load from 12,507 to 13,076 surgical procedures. For the entire survey period, the mean cumulative anaesthetic drug cost was $4.6 \%$ of the pharmacy budget, or $0.24 \%$ of the hospital budget. Analysis by drug class revealed a $\$ 51 \mathrm{~K}$ decrease in expenditures on $O A$, due to decreased utilization of fentanyl and alfentanil, and

Key words

ANAESTHESIA: cost.

From the Departments of Anaesthesia and Pharmacy, Ottawa General Hospital and The University of Ottawa, Ottawa, Ontario.

Presented in part at the 1994 Annual Meeting of The

Canadian Anaesthetists' Society, Edmonton, Alberta.

Address correspondence to: Dr. Donald R. Miller,

Department of Anaesthesia, Ottawa General Hospital, 501

Smyth Road, Ottawa, Ontario K1H 8L6.

Accepted for publication 7th June, 1994. a decrease in the price of fentanyl. The increased expenditure on INH drugs was primarily due to an increase in acquisition costs. The introduction of the new iv anaesthetic drugs $(\$ 34 \mathrm{~K}$ increase) had minimal effect on overall drug expenditures. We conclude that the implementation of simple measures such as the education of anaesthesia personnel regarding drug costs, and decreasing drug wastage, can be an effective means of controlling drug expenditures, at a time when new drugs and techniques are being introduced. The pharmacoeconomic benefits of such efforts must consider overall cost-effectiveness, including the duration and quality of recovery.

Cette enquête vise à comparer les sommes dépensées pour les drogues utilisées en anesthésie sur une période de trois ans et à évaluer l'impact des stratégies arrêtées pour réduire le coût sans cesse croissant de ces drogues. Les mesurées suggérées pour contrôler les dépenses ont été surtout fondées sur l'éducation des patrons et des résidents en matière de coûts, en insistant sur l'utilisation rationnelle des drogues les plus chères et l'élimination du gaspillage. Pour évaluer limpact de ces mesures, on a revu les budgets annuels de lhôpital, les dépenses globales de la pharmacie et les sommes accordées aux anesthésiques pour la période de 1991 à 1993. Les coûts absolus et proportionnels des drogues ont été comparés, par année, en six grandes classes: les morphiniques, les relaxants musculaires, les anesthésiques volatils, les agents intraveineux, les anesthésiques locaux et les autres drogues. De plus, les coutumes d'utilisation et les changements unitaires de prix ont été comparés pour chaque produit pour les périodes 1991-92 et 1992-93. Le coût total des produits pharmaceutiques est passé de 7,1 millions à 8,5 millions de dollars pendant ces trois années. Pendant cette même période, en anesthésie, le coût des drogues a diminué de 379,000\$ à 361,000\$, malgré l'augmentation du nombre dinterventions qui est passé de 12,507 à 13,076. Pour toutes la période de létude, le coût cumulatif moyen des anesthésiques a représenté $4,6 \%$ du budget de la pharmacie, ou $0,24 \%$ du budget de l'hôpital. L'analyse par classe a révélé une baisse de 51,000\$ des dépenses en morphiniques, causée par une diminution de l'utilisation de l'alfentanil et du fentanyl ainsi qu'à une baisse du prix du fentanyl. L'augmentation de la dépense en anesthésiques volatils a été surtout due à une augmentation du prix d'achat. Lintroduction des nouveaux anesthésiques iv 
(augmentation de 34,000\$) a eu un effet minime sur les dépenses. Nous concluons que limplantation de mesures simples comme l'éducation du personnel sur le coût des drogues et la diminution du gaspillage peuvent être efficaces pour contrôler les dépenses de pharmacie au moment où de nouveaux agents et techniques sont introduits. Le bénéfice pharmaco-économique doit considérer l'efficacité en face des coûts, la durée et la qualité du réveil incluses.

Many factors have contributed to rapidly escalating costs within the Canadian health care system, including increasingly complex and hence more costly treatments, more sophisticated technology, and an aging population who consume a greater proportion of limited resources. When coupled with decreasing fiscal resources, health care, which consumes in excess of $30 \%$ of provincial budgets, has become a target for "rationalization." Anaesthetists have become conscious that their involvement is required to develop strategies for conserving health care dollars.

Recently, the specialty of pharmacoeconomics has emerged to describe and analyze the costs of drug therapy to health care systems and society. ${ }^{1}$ This new research is used to identify, measure and compare the costs, risks, and benefits of programmes, services or therapies, and determine which strategies produce the best outcome for the resources allocated. Thus, the purpose of pharmacoeconomics should not be limited to establishing the least expensive drug therapy, but should identify the total cost of treatment. ${ }^{2}$ Jolicoeur $e t$ al. have described an approach to pharmacoeconomic analysis which includes identification of the problem, defining the outcomes and alternatives, allocating monetary values on outcomes, establishing the probability of outcome, and then using a decision analysis process. ${ }^{3}$

While pharmacoeconomic analysis will be incorporated into future anaesthesia drug trials, one method to assess the cost impact of anaesthesia practice patterns is to relate specific drug costs to total pharmacy and hospital budgets. In 1991, Torsher et al. reported the results of a survey of anaesthetic drug expenditures at the Ottawa General Hospital, a tertiary care, universityaffiliated institution. ${ }^{4}$ During the one-year survey period (1990-91), it was found that anaesthetic drug costs, for over 13,000 surgical procedures, accounted for only $5.7 \%$ of the pharmacy budget, or $0.3 \%$ of the total hospital budget. In decreasing order of expenditure, opioid analgesics, muscle relaxants, inhalational anaesthetics, and $i v$ anaesthetics accounted for the majority of costs during that year. The current survey was designed to compare annual anaesthetic drug expenditures over a three-year period to evaluate the financial impact of a cost- awareness programme, and assess the impact of the newer anaesthetic drugs on total anaesthetic drug expenditures.

\section{Methods}

In 1991, an ad hoc committee of the Department of Anaesthesia at the Ottawa General Hospital was established to examine the issue of rising costs of anaesthesia, and to make suggestions in an effort to control rising expenditures in all areas related to anaesthetic care. Regarding anaesthetic drugs, suggestions were based primarily on the education of staff and residents about drug costs, emphasizing rational use of the more expensive drugs. Specific steps included active discussion of costsaving measures during Departmental Rounds, and posting up-to-date lists of anaesthetic drug prices in each operating room. Without imposing caps or limits on drug use, staff were also asked to use low fresh gas flow rates, and take personal steps to minimize drug wastage. Nitrous oxide cylinders were removed from all anaesthetic machines, while halothane vaporizers were removed from the majority. In addition, certain drugs, including naloxone, were prepared by the hospital pharmacy in portioned vials, to minimize wastage.

To assess the impact of these measures, a review of the annual hospital budgets, global pharmacy drug expenditures, and anaesthetic drug expenditures was undertaken for the period 1991 to 1993, inclusive. Each 12month survey period corresponded to the hospital fiscal year, beginning on April lst of the previous year, and extending to March 31st of the corresponding calendar year. Data were retrieved from the hospital pharmacy, whose personnel tracked drug costs electronically for each area of the hospital. As the operating room at the Ottawa General Hospital is allocated a specific cost centre number which is different from that of the Obstetrical Suite, Recovery Room and Intensive Care Unit, it was possible to retrieve data on the costs of anaesthetic drugs used exclusively in the operating room. The costs of oxygen, nitrous oxide and medical air were, however, borne by the physical plant for the entire hospital, and were thus not incorporated in this survey.

Both the absolute and proportional costs of anaesthetic drugs were compared, by year, according to six major classes: opioid analgesics (OA), muscle relaxants (MR), inhalational anaesthetics (INH), intravenous anaesthetics (IV), local anaesthetics (LA), and a category labelled other drugs (OTH). In addition, the utilization patterns and unit price changes were compared for each drug, for the time periods 1991-92, and 1992-93. Data are presented as either cumulative totals or percentages throughout the text, figures and tables. Statistical analysis was not applied. 
TABLE I Surgical procedure volume - Ottawa General Hospital

\begin{tabular}{llll}
\hline Year & 1991 & 1992 & 1993 \\
\hline In-patients & $7785(62 \%)$ & $8860(65 \%)$ & $8411(64 \%)$ \\
Out-patients & $4822(38 \%)$ & $4670(35 \%)$ & $4665(36 \%)$ \\
Technique & & & \\
- Local & N/A & $2722(20 \%)$ & $2498(19 \%)$ \\
- Regional & N/A & $1887(14 \%)$ & $1983(15 \%)$ \\
- General & N/A & $8943(66 \%)$ & $8827(66 \%)$ \\
Annual volume & 12,507 & 13,530 & 13,076 \\
\hline
\end{tabular}

The annual procedural volume for each year, highlighting the relative proportion of in-patient vs out-patient procedures (in parentheses) as well as the relative proportion of local, regional or general anaesthetics (in parentheses). $\mathrm{N} / \mathrm{A}=$ Not available.

TABLE II Annual hospital and pharmacy expenditures

\begin{tabular}{|c|c|c|c|}
\hline Year & 1991 & 1992 & 1993 \\
\hline $\begin{array}{l}\text { Hospital expenditures } \\
\left(\$ \times 10^{6}\right)\end{array}$ & 145.2 & 162.3 & 154.3 \\
\hline $\begin{array}{l}\text { Pharmacy expenditures } \\
\left(\$ \times 10^{6}\right)\end{array}$ & $7.1(4.9 \%)^{*}$ & $8.5(5.3 \%)^{*}$ & $8.5(5.5 \%)^{*}$ \\
\hline $\begin{array}{l}\text { Anaesthesia expenditures } \\
\left(\$ \times 10^{6}\right)\end{array}$ & $0.38(5.3 \%) \dagger$ & $0.37(4.3 \%) \dagger$ & $0.36(4.3 \%) \dagger$ \\
\hline
\end{tabular}

Hospital, pharmacy and anaesthesia expenditures, by year, in millions of dollars.

*\% of hospital budget; $† \%$ of pharmacy budget.

\section{Results}

The Ottawa General Hospital is a university-affiliated, tertiary care adult hospital which provides surgical services for most procedures, exclusive of cardiac surgery. Table I highlights both the in-patient and out-patient volumes of surgical procedures for the three-year period of the survey. The total number of procedures increased by $8.2 \%$ to 13,530 from 1991 to 1992 , then decreased by $3.4 \%$ to 13,076 in 1993 . The decrease in 1993 was due to a transfer of most ophthalmology patients to a new Eye Institute which opened adjacent to the hospital. During this time, the proportion of procedures conducted on an out-patient basis was relatively constant, representing $38 \%, 35 \%$ and $36 \%$ of the totals during the years 1991,1992 , and 1993, respectively. Also, the relative proportion of surgical procedures performed under local (19-20\%), regional (14-15\%) or general anaesthesia (65-66\%) remained constant during the survey period.

Cumulative anaesthetic drug expenditures were compared with total pharmacy expenditures and the annual hospital budgets (Table II). Despite an increase in pharmacy drug budget from $\$ 7.1 \mathrm{M}$ to $\$ 8.5 \mathrm{M}$ from 1991 to 1993, anaesthetic drug expenditures actually decreased from $\$ 378.5 \mathrm{~K}$ in 1991 to $\$ 365.0 \mathrm{~K}$ in 1992 , with a further decrease to $\$ 361.0 \mathrm{~K}$ in 1993 . The cost of all anaesthetic drugs constituted $5.3 \%$ of the pharmacy drug budget in 1991 , and decreased to $4.3 \%$ of the pharmacy budget by 1992, despite a larger case load during that year. For the entire survey period, the mean cumulative anaesthetic drug cost was $4.6 \%$ of the pharmacy budget, or $0.24 \%$ of the hospital budget.

The actual costs for each major anaesthetic drug are presented in Tables III and IV, while the proportional costs of the major drug classes are displayed in Figure 1. The most striking observation was a decrease in opioid analgesic expenditures, representing $31 \%$ of total expenditures in 1991 , but only $18 \%$ in 1992, and $19 \%$ of expenditures in 1993. During this time, the amount spent on $i v$ anaesthetic drugs tripled from $5 \%$ to $15 \%$, whereas proportional expenditures on potent inhalational agents increased from $19 \%$ to $24 \%$. In contrast, expenditures on muscle relaxants remained relatively unchanged, constituting between $21 \%$ to $24 \%$ of total anaesthetic drug costs. Expenditures generated by LA and OTH were relatively stable throughout the study period.

In order to evaluate the impact of drug costs and utilization patterns on total expenditures, data were analyzed for the most commonly used anaesthetic drugs (Figures 2-5). For the opioid analgesics (Table III), total costs were $\$ 117.5 \mathrm{~K}, 66.5 \mathrm{~K}$ and $67.0 \mathrm{~K}$ from 1991 to 1993 , respectively. Unit price changes (Figure 2) were moderate except for fentanyl, which decreased by $23 \%$ in 1992, coincident with the introduction of a competitive generic compound. In 1992, use of fentanyl and alfentanil decreased by $50 \%$ and $45 \%$ respectively, whereas a corresponding increase in the use of sufentanil was observed during both 1992 and 1993.

Smaller changes in total expenditures on the muscle relaxants were observed during the survey period. Expenditures increased from $\$ 82.5 \mathrm{~K}$ to $\$ 86.5 \mathrm{~K}$ in 1992 compared with 1991, but then decreased in 1993 to $\$ 75.0 \mathrm{~K}$ (Table III). More striking, however, were changes in utilization patterns and unit price costs (Figure 3). From 1991 to 1992, similar proportional increases in unit price and total utilization were observed for atracurium, whereas expenditures on vecuronium decreased by $17 \%$, due primarily to decreased utilization. Interestingly, pancuronium expenditures increased during this time as a result of a $17 \%$ increase in utilization. In contrast, from 1992 to 1993, expenditures on atracurium decreased by $30 \%$, and vecuronium decreased by $3 \%$, both reflecting decreased utilization. The trend to increased use of longer-acting muscle relaxants continued, as reflected by a further $33 \%$ increase in pancuronium expenses from 1992 to 1993.

Important changes for the inhalational agents were also observed during the survey period. Isoflurane expend- 
TABLE III Annual anaesthetic drug expenditures

\begin{tabular}{|c|c|c|c|}
\hline & 1991 & 1992 & 1993 \\
\hline Opioid analgesics & $\$ 117,500$ & $\$ 66,500$ & $\$ 67,000$ \\
\hline Fentanyl & 58,450 & 31,399 & 26,347 \\
\hline Alfentanil & 54,891 & 29,514 & 32,474 \\
\hline Sufentanil & 4,150 & 5,399 & 7,933 \\
\hline Muscle relaxants & $\$ 82,500$ & $\$ 86,500$ & $\$ 75,000$ \\
\hline Atracurium & 44,017 & 51,680 & 36,241 \\
\hline Vecuronium & 30,388 & 25,078 & 24,415 \\
\hline Succinylcholine & 2,675 & 3,453 & 5,339 \\
\hline Pancuronium & 2,939 & 3,512 & 4,679 \\
\hline Metocurine & 1,425 & 1,852 & 1,966 \\
\hline d-tubocurarine & 877 & 968 & 2,225 \\
\hline Inhalational anaesthetics & $\$ 71,500$ & $\$ 76,000$ & $\$ 88,000$ \\
\hline Isoflurane & 59,873 & 66,960 & 74,912 \\
\hline Enflurane & 11,234 & 9,096 & 12,975 \\
\hline Halothane & 123 & 52 & 122 \\
\hline Intravenous anaesthetics & $\$ 20,500$ & $\$ 42,000$ & $\$ 54,500$ \\
\hline Propofol & 3,821 & 24,416 & 31,109 \\
\hline Thiopentone & 11,597 & 10,141 & 15,914 \\
\hline Midazolam & 3,655 & 5,754 & 6,116 \\
\hline Ketamine & 1,201 & 1,593 & 1,197 \\
\hline Diazepam & 28 & 44 & 28 \\
\hline Local anaesthetics & $\$ 31,000$ & $\$ 34,500$ & $\$ 34,000$ \\
\hline Lidocaine $\mathrm{CO}_{2} 2 \%$ & 9,562 & 9,502 & 8,129 \\
\hline Lidocaine $5 \%$ & 3,953 & 4,215 & 4,281 \\
\hline Bupivacaine $0.5 \%$ & 3,219 & 3,907 & 4,129 \\
\hline Lidocaine $1 \%$ & 2,820 & 3,062 & 3,677 \\
\hline Bupivacaine $0.25 \%$ & 1,591 & 2,076 & 2,449 \\
\hline Lidocaine $1.5 \%$ epi & 1,790 & 2,169 & 1,873 \\
\hline Lidocaine $2 \%$ & 1,527 & 2,081 & 1,475 \\
\hline Lidocaine $1 \%$ epi & 1,366 & 1,516 & 1,486 \\
\hline Bupivacaine $0.5 \%$ epi & 632 & 783 & 1,998 \\
\hline Bupivacaine $0.25 \%$ epi & 651 & 895 & 1,554 \\
\hline Lidocaine $2 \%$ epi & 858 & 870 & 696 \\
\hline Chloroprocaine & 746 & 746 & 833 \\
\hline Tetracaine & 906 & 667 & 143 \\
\hline Lidocaine $1.5 \%$ & 687 & 568 & 290 \\
\hline Bupivacaine $0.75 \%$ & 0 & 905 & 578 \\
\hline Bupivacaine $0.75 \%$ & 215 & 472 & 431 \\
\hline Dextrose $10 \%$ for spinals & 187 & 182 & 109 \\
\hline Lidocaine $0.5 \%$ & 46 & 54 & 73 \\
\hline Others & 855,500 & $\$ 59,500$ & $\$ 42,500$ \\
\hline Vasoactive drugs & 17,356 & 19,540 & 14,209 \\
\hline MR reversal drugs & 15,016 & 15,802 & 13,444 \\
\hline Miscellaneous & 23,125 & 23,962 & 14,833 \\
\hline
\end{tabular}

Annual expenditures (in dollars) for each drug, with totals highlighted and rounded to the nearest $\$ 500$.

itures increased by $12 \%$ from 1991 to 1992 , and again by another $12 \%$ from 1992 to 1993 , largely due to increases in unit price (Figure 4). Conversely, the utilization and proportional expenditures of enflurane decreased by $22 \%$ and $19 \%$ from 1991 to 1992 , respectively. However,
TABLE IV OTH drug expenditures

\begin{tabular}{|c|c|c|c|}
\hline & 1991 & 1992 & 1993 \\
\hline$M R$ reversal drugs & $\$ 15,000$ & $\$ 16,000$ & $\$ 13,500$ \\
\hline Neostigmine & 6,289 & 6,912 & 5,047 \\
\hline Edrophonium & 5,357 & 3,827 & 3,220 \\
\hline Glycopyrolate & 2,157 & 3,608 & 3,541 \\
\hline Atropine & 1,095 & 1,094 & 1,202 \\
\hline Pyridostigmine & 118 & 361 & 434 \\
\hline Vasoactive drugs & $\$ 17,500$ & $\$ 19,500$ & $\$ 14,000$ \\
\hline Ephedrine & 6,381 & 7,107 & 5,663 \\
\hline Propranolol & 4,643 & 3,738 & 1,632 \\
\hline Xylocard & 2,284 & 2,919 & 1,503 \\
\hline Labetolol & 1,767 & 2,715 & 1,992 \\
\hline Epinephrine & 1,074 & 972 & 641 \\
\hline Nitroglycerine & 153 & 747 & 435 \\
\hline Phenylephrine & 191 & 430 & 522 \\
\hline Hydralazine & 422 & 497 & 168 \\
\hline Esmolol & 0 & 0 & 1,036 \\
\hline Isoprotereno] & 233 & 213 & 396 \\
\hline Nitroprusside & 208 & 202 & 221 \\
\hline Miscellaneous drugs & $\$ 23,000$ & $\$ 24,000$ & $\$ 15,000$ \\
\hline Droperidol & 8,663 & 7,191 & 3,217 \\
\hline Lidocaine jelly & 3,245 & 3,246 & 3,323 \\
\hline Lidocaine MD spray & 1,472 & 2,162 & 3,125 \\
\hline Naloxone & 1,915 & 4,959 & $-499 *$ \\
\hline Protamine & 1,069 & 2,171 & 1,423 \\
\hline Heparin & 943 & 1,114 & 942 \\
\hline Lacrilube & 1,017 & 797 & 709 \\
\hline Dantrolene & 1,494 & 0 & 593 \\
\hline $\mathrm{H}_{2} \mathrm{O}$ injectable amps & 461 & 382 & 256 \\
\hline
\end{tabular}

OTH subgroup, showing actual annual expenditures (in dollars) for each drug, with totals highlighted and rounded to the nearest $\$ 500$.

*Negative balance resulting from credit for drug returned to supplier.

this pattern reversed the following year, as reflected by a $30 \%$ increase in enflurane utilization, and a $43 \%$ increase in expenditure. Despite the marked differences in drug use patterns, isoflurane remained the most commonly used volatile anaesthetic during the survey, with total expenditures of $\$ 74.9 \mathrm{~K}$ in 1993 , compared with the $\$ 13.0 \mathrm{~K}$ spent on enflurane during the same year (Table III). Halothane expenditures were minimal.

For the iv anaesthetic drugs, total annual expenditures were less than those associated with the other classes of drugs, but proportional expenditures increased to a much greater extent. From 1992 to 1993, expenditures on $\dot{w}$ anaesthetic drugs effectively doubled from $\$ 20.5 \mathrm{~K}$ to $\$ 42.0 \mathrm{~K}$, then increased further in 1993 to reach a total of $\$ 54.5 \mathrm{~K}$ (Table III). Proportional expenditures are shown in Figure 5. From 1991 to 1992, midazolam expenditures increased by $57 \%$, due to a $44 \%$ increase in utilization and a $9 \%$ increase in unit cost. However, midazolam utilization tended to stabilize during 1992 to 1993 , with only a $6 \%$ increase in expenditure during that 


\section{Annual Expenditures}

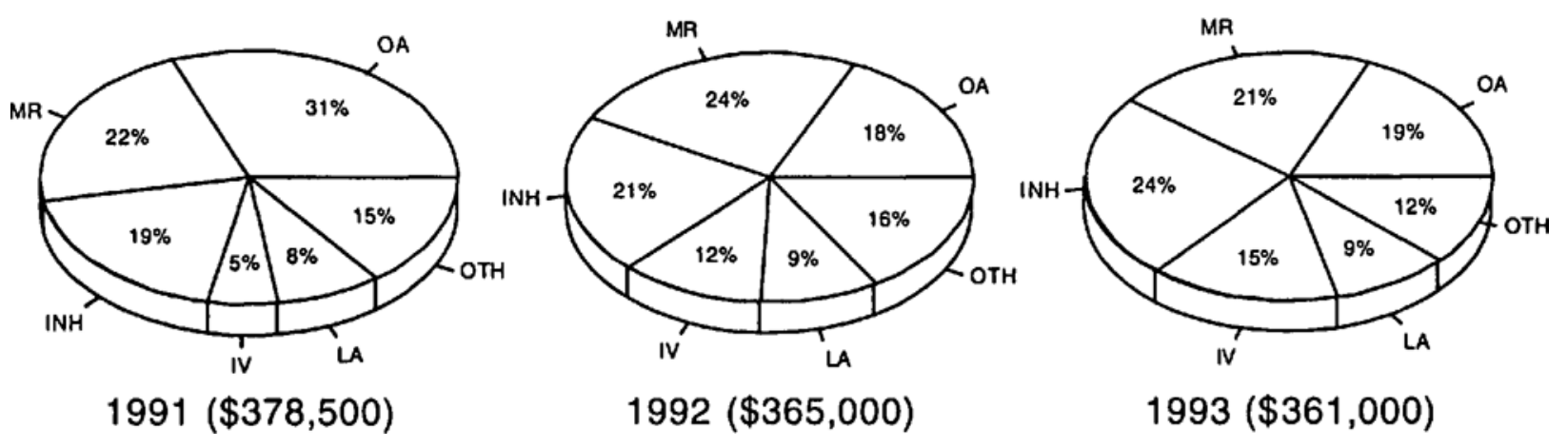

FIGURE 1 Annual anaesthetic expenditures (parenthesis) showing the relative percentage contribution by class (OA: opioid analgesics; MR: muscle relaxants; INH: inhalational anaesthetics; IV: intravenous anaesthetics; LA: local anaesthetics; OTH: others).

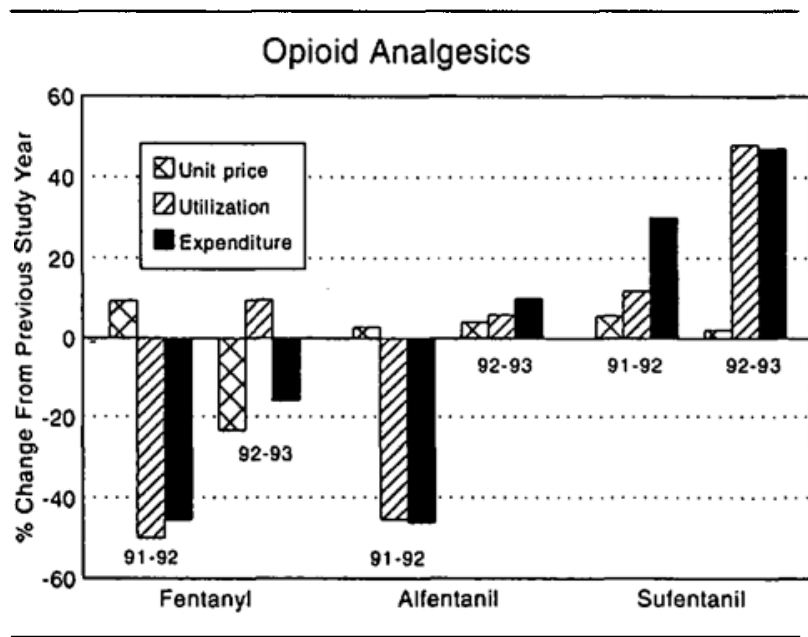

FIGURE 2 Influence of unit price and utilization on total expenditures of fentanyl, alfentanil and sufentanil. A positive value reflects an increase over the previous year.

time period. As propofol was not available on hospital formulary until January 1991 (ten months into the fiscal year), a 1991-1992 comparison of unit cost and utilization was not done for this drug. However, from 1992 to 1993 , propofol expenditures increased by $23 \%$, due mostly to an $18 \%$ increase in utilization. Interestingly, thiopentone expenditures decreased somewhat in 1992, but then increased markedly from 1992 to 1993 , as a result of a $47 \%$ increase in utilization.

Finally, several interesting trends were observed on reviewing expenditures within the OTH subgroup. Notable was a decrease in droperidol expenditures from approximately $\$ 8.7 \mathrm{~K}$ in 1991 to $\$ 7.2 \mathrm{~K}$ in 1992 , with a further decrease in 1993 to $\$ 3.2 \mathrm{~K}$ (Table IV). The decrease in expenditures resulted primarily from decreased utiliza-

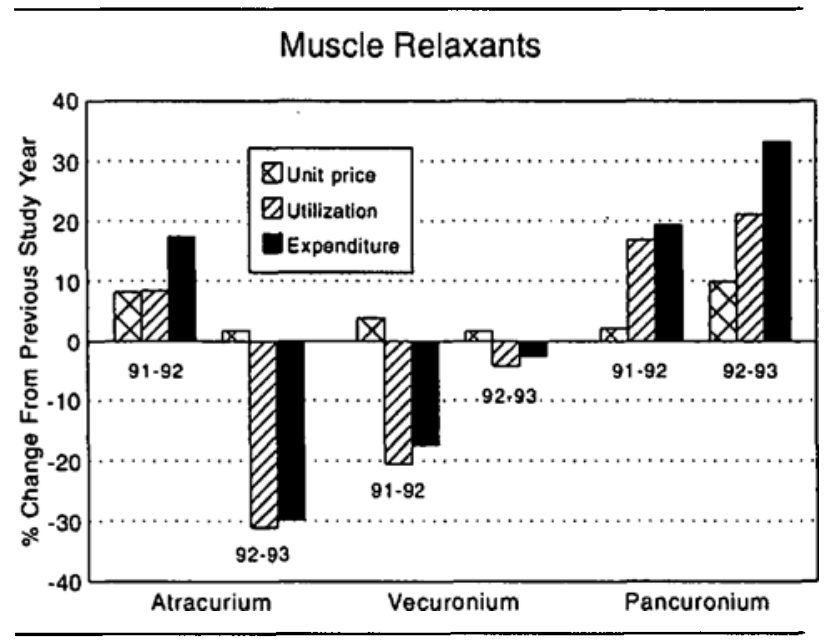

FIGURE 3 Influence of unit price and utilization on total expenditures of atracurium, vecuronium and pancuronium. A positive value reflects an increase over the previous year.

tion, by a factor of $22 \%$ from 1991 to 1992 , and by a further 58\% from 1992 to 1993.

\section{Discussion}

While anaesthesia drug costs account for a relatively small proportion of total hospital expenditures $(0.2-0.33 \%)$, this share appears to be increasing at a number of institutions across Canada. ${ }^{5}$ Clearly, one important area where anaesthetists can directly influence health care costs is through their practice patterns, including selection of anaesthetic drugs. This has been an issue of considerable interest, due to the recent introduction of shorter-acting drugs such as propofol, midazolam, alfentanil, atracurium and vecuronium, and the soon-tobe-released drugs desflurane, mivacurium and rocuro- 
Inhalational Anaesthetics

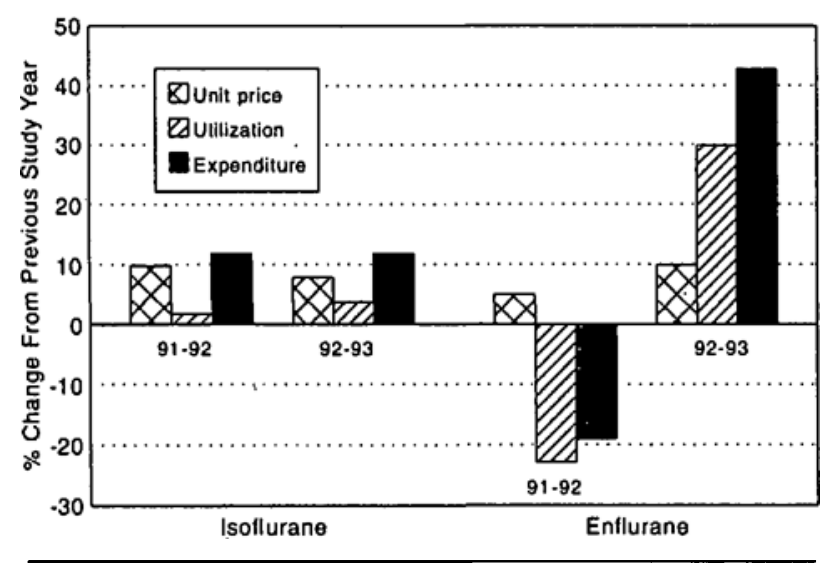

FIGURE 4 Influence of unit price and utilization on total expenditures of isoflurane and enflurane. A positive value reflects an increase over the previous year.

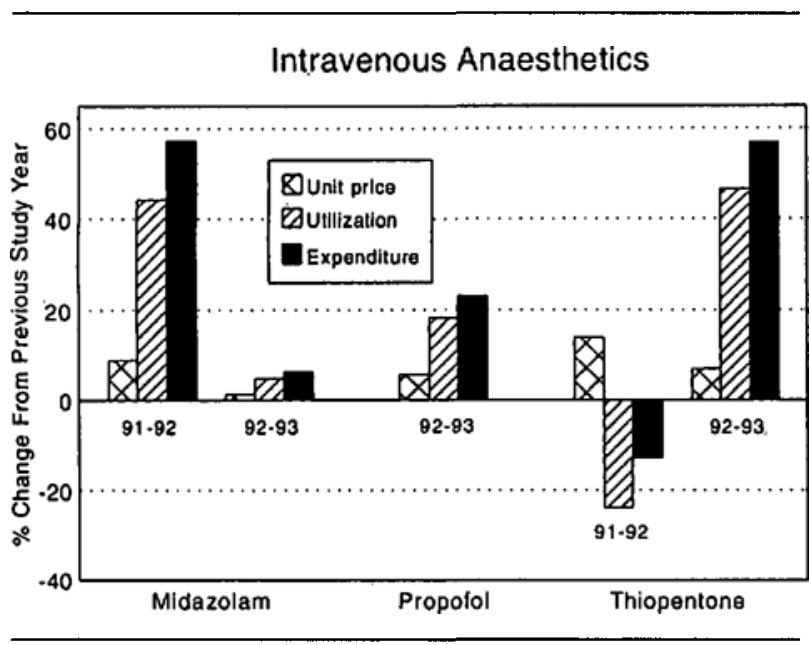

FIGURE 5 Influence of unit price and utilization on total expenditures of midazolam, propofol, and thiopentone. A positive value reflects an increase over the previous year. Due to the late introduction of propofol in the 1991 survey year, 1991-92 comparison was omitted.

nium. In an effort to encourage a more rational and parsimonious selection of drugs, our research group has been reviewing, on an ongoing basis, anaesthetic drug expenditures at the Ottawa General Hospital. ${ }^{4}$ Whereas total pharmacy costs at this tertiary care, university-affiliated hospital have increased from $\$ 7.1 \mathrm{M}$ to $\$ 8.5 \mathrm{M}$ during the period 1991 to 1993 (representing an increase from $4.9 \%$ to $5.5 \%$ of the total hospital budget), the cost of anaesthetic drugs actually decreased from $\$ 378.5 \mathrm{~K}$ to $\$ 361.0 \mathrm{~K}$, despite a gradual increase in total case load from 12,507 to 13,076 procedures during the same time period. These costs are well within the range of costs reported elsewhere, ${ }^{5}$ constituting approximately $0.24 \%$ of the total hospital budget for the institution.

Amongst several factors, it was assumed that education of staff and residents about drug costs contributed to the reduction in expenditures, at a time when the unit price of most anaesthetic drugs increased, and new anaesthetic drugs were introduced. The most notable observation was the change in the pattern of opioid analgesic usage. A reduction of $\$ 51 \mathrm{~K}$ in expenditures from 1991 to 1992 resulted from the decreased use of fentanyl and alfentanil, with an associated increase in the usage of sufentanil. This change in practice pattern may have been due, in part, to an enhanced appreciation of postinfusion kinetics, resulting from two important publications which appeared at the beginning of the survey period. ${ }^{6,7}$ Another possible explanation for the decreased use of fentanyl and alfentanil may have been a modification of balanced anaesthetic regimens, including an increased dependence on propofol in conjunction with lower doses of opioid analgesics. In addition, generic fentanyl became available in 1992, resulting in a decrease in unit price. Finally, a decrease in drug wastage may also have contributed to the curtailed costs, although wastage was not measured.

The observed decrease in expenditures in 1992 was also remarkable because 1992 was the first time when propofol was available for an entire fiscal year. Although propofol is more expensive than thiopentone, we feel this cost differential to be justified due to an improved quality of care attributable to a reduced incidence of nausea and vomiting, and a smooth and rapid recovery profile. ${ }^{8,9}$ Recent reports suggest that pharmacy costs for anaesthetic drugs have not been greatly affected by the introduction of propofol. ${ }^{10}$ At the Ottawa General Hospital, propofol expenditures accounted for almost $60 \%$ of $i v$ anaesthetic drug costs in 1992. During this survey, no attempt was made to assess the utilization of propofol for induction alone, or induction plus maintenance of anaesthesia. Clearly, propofol infusions for maintenance of anaesthesia will increase drug expenditures, but this technique may lead to savings in other areas. For example, it has recently been shown that for outpatient surgery, propofol/nitrous oxide anaesthesia provides a reduction in recovery time, a decreased incidence of postoperative nausea and vomiting, and a decrease in nursing workload, compared with patients who receive thiopentone/isoflurane anaesthesia. " However, to realize these savings, policies must be reviewed, and criteria for discharge must be based on recovery criteria rather than a designated time. In this regard, the Department of Anaesthesia at the Ottawa General Hospital is considering the adoption of a post-anaesthetic discharge scoring system (PADS), as advocated by Chung et al., ${ }^{12}$ in order 
to evaluate patients for discharge following day surgery procedures.

The introduction of propofol may also partly account for a decrease or moderation in expenditures of other drugs. Specifically, there was a steady increase in expenditures on the potent inhalational agents during the survey period, but this resulted from increases in unit price, and not utilization. It is possible that the addition of propofol to formulary may have partially offset a further increase in expenditures on potent inhalational agents. In addition, there was a $63 \%$ decrease in expenditures on droperidol during the same time period. The anti-emetic effects of propofol ${ }^{13}$ have caused most anaesthetists at the survey hospital to abandon the use of droperidol as a routine anti-emetic medication for either in-patient or out-patient procedures.

Regarding muscle relaxants, an increase in expenditures in 1992, compared with 1991, can be accounted for by increases in both the cost and utilization of atracurium. However, the overall increase in expenditures on this class of drugs was tempered somewhat by a substantial decrease in the use of vecuronium, as well as increased use of the longer-acting and less expensive pancuronium. In 1993, a reduction in the use of atracurium, and decreasing use of vecuronium were observed, associated with a further increase in the use of pancuronium. Although these changing patterns in the use of muscle relaxants resulted in a cost reduction of $\$ 7.5 \mathrm{~K}$ from 1991 to 1993, one concern is that increased use of long-acting muscle relaxants may result in a higher incidence of residual neuromuscular block postoperatively, as has been established by other investigators. ${ }^{14}$ This is a most important issue, as respiratory complications remain a major contributor to morbidity in the Recovery Room, and persistent neuromuscular block is one of the most common causes of respiratory failure in the postoperative period. Patient safety must always take precedence over economic considerations.

From these observations, it is apparent that the true cost of any anaesthetic technique is more than the cost of drug acquisition. Direct hospital pharmacy costs, alternative treatments, and consumption of other aspects of health care must also be evaluated. In addition, the risks and complications resulting from each type of treatment need to be considered. Recently, the new specialty of pharmacoeconomics has emerged to describe and analyze the costs of drug therapy to health care systems and society. ${ }^{1,3,15}$ This new research is used to identify, measure and compare the costs, risks, and benefits of programmes, services or therapies and determine which alternative produces the best outcome for the resources invested. From this science, a variety of new terms have arisen:
1 Cost-minimization analysis Cost-minimization analysis is conducted when the outcomes of consequences of two or more interventions have been determined to be equal. This allows one to compare only the inputs or costs of each alternative when efficacy and side effects are similar (e.g., among generically equivalent drugs for which patient outcomes have been shown to be the same).

2 Cost-benefit analysis. In cost-benefit analysis, all costs (inputs) and benefits (consequences) or alternatives are measured in monetary terms. The outcome may be expressed as a ratio (benefit to cost), or in terms of net cost or benefit (benefit minus cost). The obvious problem with this type of analysis is the difficulty of converting some non-monetary units. Because of this, cost-effectiveness analysis is more commonly used.

3 Cost-effectiveness analysis. Cost-effectiveness analysis differs from cost-benefit analysis in that outcomes are measured in non-monetary units, which must be identical for each alternative. The measured outcomes are then expressed in terms of the cost/unit of success or effect, such as the cost/hr of reduced nursing care time, or the cost $/ \mathrm{mmHg}$ change in blood pressure for antihypertensive therapy.

4 Cost-utility analysis. Cost-utility analysis is a method that accounts for effectiveness, while integrating patient preferences and satisfaction. For instance, postoperative nausea and vomiting are of concern in costeffectiveness analysis because of the added cost involved in their treatment. In contrast, cost-utility analysis evaluates nausea and vomiting not only for the additional costs of treatment, but for the impact they have on the patient's life.

5 Cost-of-illness analysis. This type of analysis attempts to identify all direct and indirect costs of treating a certain disease or illness.

When used correctly, pharmacoeconomic analysis can become a powerful tool in the evaluation of new anaesthetic drugs and techniques. In a recent study comparing the haemodynamic and pharmacodynamic activity of doxacurium and pipecuronium with pancuronium, it was shown that doxacurium and pipecuronium were less likely than pancuronium to increase heart rate during induction of cardiac anaesthesia. ${ }^{16}$ Although these two new muscle relaxants did not produce haemodynamic aberrations requiring additional drug interventions, it was found that they were more than ten times the cost of pancuronium. This represents a marked inequality when considered from a cost-effective analysis.

In addition to addressing pharmacoeconomic aspects, a number of simple cost-saving measures have been adopted by our department. One example has been the introduction of a more cost-effective preparation of nal- 
oxone. Before 1991, naloxone was supplied on the anaesthetic drug carts in $2 \mathrm{mg} / 2 \mathrm{ml}$ ampoules, at a cost of approximately $\$ 37 /$ ampoule. Since a typical treatment dose is only $40-120 \mu \mathrm{g} i v$, considerable waste was the rule. In response, the hospital pharmacy now prepares

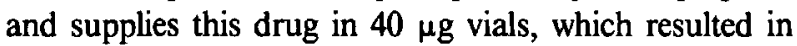
a saving of $\$ 5.5 \mathrm{~K}$ in 1993 , compared with 1992 . Other steps have been taken to reduce costs. An updated drug list with costs highlighted is now provided in each OR. Fresh gas flows have been reduced, and nitrous oxide cylinders have been removed from the anaesthetic machines. In addition, local anaesthetics are now diluted to the desired concentration to achieve cost savings of up to $50 \%$ per treatment.

One inherent limitation in reporting this type of data from one institution is the impact of that institution's practice pattern on the results. Accordingly, the findings of this survey may not be applicable to other hospitals, even if they are tertiary care institutions. This issue obviously limits the quantitative application of these data to other departments of anaesthesia, although the principles of cost-minimization strategies should still be relevant.

Should we be concerned about the costs of anaesthesia? As emphasized by Orkin, in value-based anaesthesia care, consideration of costs is neither unethical nor immoral, and economic considerations must be part of clinical decision making. ${ }^{17}$ In this regard, both indirect as well as direct costs must be considered, in addition to the quality of care which is provided, but which is so often difficult to measure. From the present survey, there is little doubt that anaesthetists can, and do, have a substantial impact on health care costs. By becoming knowledgeable about the important issues, we, as a specialty, can be pro-active in working with our medical colleagues, administrators, and government in continuing to provide the highest levels of anaesthetic care to our patients, in a cost-effective manner.

We conclude that the implementation of simple measures such as the education of anaesthesia personnel regarding drug costs, and decreasing drug wastage, can be an effective means of controlling drug expenditures, at a time when new drugs and techniques are being introduced. The pharmacoeconomic benefits of such efforts must consider overall cost-effectiveness, including the duration and quality of recovery. This will be the focus of considerable future research.

\section{References}

1 Bootman JL, Larson LN, McGhan WF, Townsend RJ. Pharmacoeconomic research and clinical trials: concepts and issues. Ann Pharmacother 1989; 23: 693-7.

2 Johnstone RE, Martinec CL. Costs of anesthesia. Anesth Analg 1993; 76: 840-8.
3 Jolicoeur LM, Jones-Grizzle AJ, Boyer JG. Guidelines for performing a pharmacoeconomic analysis. Am J Hosp Pharm 1992; 49: 1741-7.

4 Torsher L, Martineau RJ, Tierney M, Hopkins HS, Miller $D R$. A survey of anaesthetic drug expenditures. Can $\mathbf{J}$ Anaesth 1992; 39: Al13.

5 Hudson RJ, Friesen RM. Health care "reform" and the costs of anaesthesia. Can J Anaesth 1993; 40: 1120-5.

6 Shafer SL, Varvel JR. Pharmacokinetics, pharmacodynamics, and rational opioid selection. Anesthesiology 1991; 74: 53-63.

7 Hughes MA, Glass PSA, Jacobs JR. Context-sensitive half-time in multicompartment pharmacokinetic models for intravenous anesthetic drugs. Anesthesiology 1992; 76: 334-41.

8 Doze VA, Westphal LM, White PF. Comparison of propofol with methohexital for outpatient anesthesia. Anesth Analg 1986; 65: 1189-95.

9 Whïte $P F$, Watcha $M F$. Are new drugs cost-effective for patients undergoing ambulatory surgery? (Editorial). Anesthesiology 1993; 78: 2-5.

10 Cooper CG, Maxwell $V$. Anaesthetic drug costs are not increased by propofol (Letter). Can J Anaesth 1992; 39: 1000.

11 Sung $Y-F$, Reiss $N$, Tillette $T$. The differential cost of anesthesia and recovery with propofol-nitrous oxide anesthesia versus thiopental sodium-isoflurane-nitrous oxide anesthesia. J Clin Anesth 1991; 3: 391-4.

12 Chung $F$, Ong D, Seyone C, Mati N, Chan V. PADS - a discriminative discharge index for ambulatory surgery. Anesthesiology 1991; 75: Al105.

13 Borgeat A, Wilder-Smith OHG, Saiah $M$, Rifat $K$ Subhypnotic doses of propofol possess direct antiemetic properties. Anesth Analg 1992; 74: 539-41.

14 Bevan DR, Smith CE, Donati F. Postoperative neuromuscular blockade: a comparison between atracurium, vecuronium, and pancuronium. Anesthesiology 1988; 69: 272-6.

15 Detsky AS, Naglie IG. A clinician's guide to costeffectiveness analysis. Ann Intern Med 1990; 113: 147-54.

16 Rathmell JP, Brokker RF, Prielipp RC, Butterworth JF IV, Gravlee GP. Hemodynamic and pharmacodynamic comparison of doxacurium and pipecuronium with pancuronium during induction of cardiac anesthesia: does the benefit justify the cost? Anesth Analg 1993; 76: 513-9.

17 Orkin FK. Moving toward value-based anesthesia care. J Clin Anesth 1993; 5: 91-8. 